\title{
Is There a Skill Constraint in the Diffusion of Microelectronics?
}

\author{
Raphael Kaplinsky
}

\section{Introduction}

In this contribution we aim to focus on the skill implications of the introduction of a new microelectronics based technology which involves a radically different work practice from that involved in the established processes. The technology referred to is computer aided design (CAD) and relates to the dual activities of design and draughting. Before we discuss these skill implications, we first describe the technology, summarise the results of a major study involving field research in Europe and North America [Kaplinsky 1982 ] and assess its impact (and by implication, that of microelectronics based technologies in general) on developing country comparative advantage.

\section{Computer aided design technology}

CAD is a particularly good example of a software intensive industry. Building on a fairly standard set of microelectronic hardware (predominantly minicomputers) and peripheral components (television screens, computer memory, drawing devices and electronic drawing boards) systems are available to undertake a wide range of tasks to assist designers and draughtspersons in their work. This assistance is of two major sorts. The first involves basic graphic software which speeds up the process of drawing; the second involves a wide variety of applications programs to meet particular design needs in all sectors of engineering (electrical, civil, mechanical, chemical), cartography, business analysis and animation.

The price of these systems starts from around $\$ 30,000$ for a single terminal system which is suitable only for drawing, to around $\mathbf{\$ 1 . 5} \mathrm{mn}$ for a 30 terminal system which provides both a wide variety of analytical applications programs and a capability to undertake numerous, unrelated batch processing tasks such as payrolls and customer billing. Of these prices, around 30 per cent is hardware; the rest comprise of overheads and a considerable input of software. Some of the turnkey vendors have accumulated well in excess of 1,000 person years of software with over seven million lines of software code in the suite of basic graphics and applications software which they offer.

The origins of this industry lie in the aerospace and defence sectors of the late 1950s and 1960s. By the early 1970 s CAD began to be used in the electronic sector, diffusing to mechanical engineering and cartography over the past five years. The industry expects the civil engineering and architectural sectors to be the major growth point in the second half of the $1980 \mathrm{~s}$. The achieved growth of this sector has been quite remarkable. Having reached around $\$ 80 \mathrm{mn}$ in 1976 , the sector 'took off' with the value of output reaching around \$1 bn in 1980. Projections of sales value for 1984 are between $\$ 5$ bn and $\$ 8$ bn. By comparison, the projection for global sales of robots is only $\$ 2$ bn by 1990 , and only $\$ 4$ bn for colour TVs in the USA in 1984. As another indicator of the phenomenal growth of the CAD sector, if the industry had grown at the same rate as IBM between 1976 and 1980 , its sales would have only been around $\$ 120 \mathrm{mn}$ in 1980, and if it had followed the same growth path as DEC (the most successful of the minicomputer firms, the 'success story' of the 1970 s), its size in 1980 would only have been around $\$ 250 \mathrm{mn}$.

This very remarkable growth path follows in part from the benefits arising to users (see below). But it also follows from the fact that CAD has a key role to play in the development of the automated factory, since it is in the design phase that the data base for production and information control is defined. Hitherto there has not been great progress in the development of automated factories, but with the growing maturity of $\mathrm{CAD}$ and flexible manufacturing systems, most of the components of these automated systems now exist. The cutting edge of technological progress lies now within the sphere of organisation since the synergies between various parts of the system, and the implications for altered staffing and skills patterns, requires systems' reorganisation. The bottlenecks in this phase of automation are probably as much social as technical.

\section{The benefits to use}

Assessing the benefits of using the technology is problematical since there are such a wide variety of uses, since design is essentially a craft-based activity (and is hence susceptible to variation, as are all labourintensive tasks) and since the technology has only recently 'matured'. Nevertheless it is possible to make a preliminary attempt at classifying the types (and

Bulletin, 1982, vol 13 no 2, Institute of Development Studies, Sussex 
even the extent) of benefits accruing to user-firms (but not necessarily to the workers involved!). Four major types of benefits emerge, namely in:

\section{Draughting}

Average productivity gains were found to be in the region of 3:1. Given the cost of the equipment, a three year pay-back period and this level of productivity gains, we estimate that it pays firms to use CAD on a two shift basis when the gross payroll cost (ie including overheads) of draughtspersons/ designers exceeded $\$ 5,500$. This is a level which is exceeded in many developing countries.

\section{Desigm}

Here CAD offers a number of different benefits depending upon the sector. In some sectors (eg electronics, aerospace) it is essential-the product

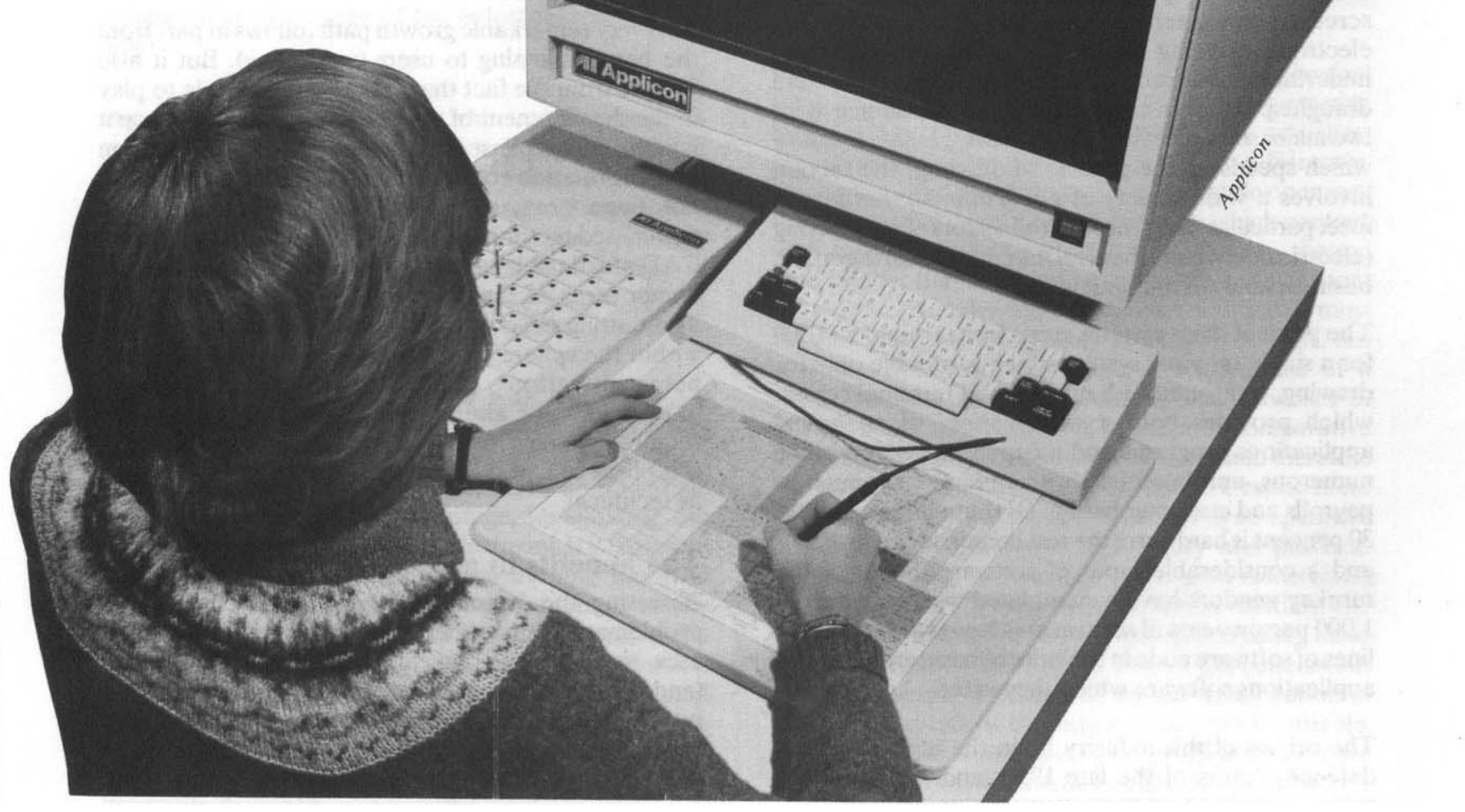


could not be produced without it. In other sectors CAD allows for greater optimisation of product design (eg reducing wind resistance of motor cars which improves fuel efficiency). In almost all firms visited CAD played a crucial role in reducing the lead-time required to get the product on to the market.

\section{Downstream benefits}

The use of CAD offers a wide range of benefits (which at this early stage are still largely potential, rather than realised) in downstream activities such as setting machine controls automatically, testing products and helping in the control of inventories.

\section{Control}

From management's point of view CAD provides a very important benefit in enhancing control over the design and draughting staff and, by allowing for selective access to the design details, in reducing the flow of technical secrets to competitors.

\section{Impact of CAD on comparative advantage}

Given that design and draughting are only subsets (albeit key ones) of the process of producing and marketing an attractive product, it is difficult to argue that it alone will affect the international division of labour. Moreover given developments in communications technologies (notably via satellites) it is entirely feasible to set up design facilites in one continent and production plants in another. We are consequently forced to see CAD as an example of one of many emerging microelectronics based technologies and to argue, ex hypothesis, that the conclusions derived from this technology are relevant to those derived from other ones.

To the extent that it is possible to assess the likely path of diffusion of CAD technology we are drawn to the following firm conclusion. The technology is likely to diffuse most rapidly to precisely those sectors in which developing country manufactured exports grew so rapidly in the 1970s [Kaplinsky 1982]. The traditionalmanufactures sectors (ie shoes, garments, leather products and semi-manufactured textiles) are likely to be relatively less affected by $\mathrm{CAD}$ technology - a view which mirrors the conclusions of Hoffman and Rush in their article in this Bulletin. What this means, therefore, is that the emerging comparative advantage of the NICs in higher technology sectors is likely to be undercut in the 1980s, if other microelectronics-based technologies offer similar benefits to users and diffuse in a similar pattern as CAD.

\section{Skill implications of using CAD technology}

In a growing number of sectors, therefore, CAD either already is, or is rapidly becoming, a mandatory technology if firms are to compete effectively in increasingly competitive markets. Our attention is thus naturally drawn towards the skills required to make efficient use of this radical new technology. Earlier discussion pointed out that, as with many new electronic technologies, the gains derived from using CAD are felt not only within the narrow confines of draughting but span the whole system of factory organisation. Consequently in discussing the skills involved in its efficient utilisation, we must consider both operator-skills and management skills as well as the learning curves which are involved. At the same time a software intensive technology such as CAD requires extensive back-up and service-skills from the suppliers if it is to be run efficiently.

\section{Skills}

i) Operator skills - There was a fairly strong consensus amongst all users visited that, at the worst, the skills required to operate $\mathrm{CAD}$ systems are the same as those involved in manual systems, and in more favourable circumstances, the required skills are lower than those with which traditional draughtspeople are equipped. As far as draughting is concerned, CAD (like other forms of mechanisation) deskills the job and reduces it to machine operation. By contrast in the case of analysis and design, by removing the unskilled element, CAD distils the skill component for concentrated attention by the designer. We see here a difference in the position of draughtspeople and designers - the skills of the draughtsperson are, in effect, boring constraints for the designer.

Both operators and management conclude that $\mathrm{CAD}$ reduces the skill component in draughting because it removes the craft element (requiring extensive practice) associated with individually-tailored layouts and individually developed lettering. This is not to say that CAD has no specific skill requirements, but that the type and levels of skill are altered. Most management reported that typing skills were an advantage, given that all CAD systems have an alphanumeric keyboard for entering at least some of the data. But, as far as management is concerned, attitude and flexibility are more important attributes; some management felt (with no apparent justification) that these were a function of youth; one system manager claimed that 'females were less flexible and dexterous' despite the existence of many female CAD operators, particularly in the USA. Finally one firm, which has a particularly rapid screen response time, argues that manual dexterity is an important attribute - thus while the average IBM CAD operator works at around 30 interrupts per minute, the best UK operator has been timed at 70 per minute and best US performance is 100 interrupts per minute. Thus it was the view of most management that although a good draughtsperson makes a good CAD 
operator, the CAD system was sometimes able to make a good operator out of a bad draughtsperson (eg someone who was sloppy at lettering).

ii) Management skills - The skills required by managers (as opposed to operators) of the CAD system are of a more substantive nature, for three reasons. Firstly, as we saw in the previous section, many of the benefits of $\mathrm{CAD}$ are felt downstream. The current state-of-theart of CAD technology is generally one in which the basic draughting-gains have been mastered and the cutting-edge of progress lies in capturing these downstream benefits. While this latter task is partly a function of improved software, it also requires a changed attitude by management which is still feeling its way towards new forms of systems organisation. Secondly, even within the draughting/design stage, management has an important role to play in improving productivity. Whilst operators are able to build-up their skills until they can use the CAD system rapidly, for the real benefits to be obtained the draughting office has to be well-organised. And finally, management argues that it has an important function to perform in evening out the performance of individual operators into a curve of continuous and harmonised growth for the CAD system as a whole.

Given these taxing demands upon management, it is not clear that any particular skills (different, that is, to pre-CAD skills) are required. However a vision of systems gains and the power to implement organisational changes are of critical importance. And to the extent that these attributes are necessary it is not evident whether these can be formally learnt or whether they are acquired through direct experience.

\section{Back-up services}

CAD systems are new, different and software-intensive. Users consequently require a great deal of back-up assistance from suppliers until their systems function efficiently, particularly when the innovating firm is not experienced in using analogous types of equipment (such as automatic testing equipment) -indeed, this ability to supply assistance to users is a major competitive factor in the supplying industry. For example, the major supplier aims to have in Europe one software-support engineer for every eight systems in use and one hardware maintenance engineer for every four systems. In addition it has a further 24 software staff in the UK alone who service the home market and parts of the European market.

The services offered by these suppliers relate predominantly to software. Most suppliers reported that over 50 per cent of software problems turn out, on inspection, to reflect the 'ignorance' of users. But in addition to the ongoing support services which suppliers offer, the growth of users' systems efficiency is enhanced by specialised courses which all suppliers provide (usually at a price) as well as by regular users' groups in which users can exchange experience and bring collective pressure to bear on suppliers. The dominant conclusion which emerges from all this is that 'closeness' to $\mathrm{CAD}$ suppliers and users is important for efficient use, requiring an ongoing 'handholding' relationship.

\section{The learning curve}

Obviously the learning curve of both operators and management depends largely upon the use to which the CAD system is put. For example a system used for pure draughting is generally easier to assimilate than one used for design or the capturing of downstream benefits. On the other hand, such limited uses (characteristic of unimaginatively managed systems) may well reflect the inability of management to learn to use CAD effectively. As a general observation, it appears as if there is a trade-off between the rate of learning (of both operators and managers) and the ultimate success with which the system is used. The too-rapid definition of procedures which assist in obtaining early gains in productivity, has the effect of boxing-in the future potential of the system.

The slope of the learning curves can be steepened in a number of different ways. One is to send both operators and managers away on courses, or to institute formal in-house training programmes. In fact most CAD suppliers included a series of basic courses in their sales price and offered a range of specialised courses for particular applications programs. A second strategy, generally pursued by enterprises for whom rapid progress is vital, is to poach expertise from existing CAD users. This presents gains to both the purchasing firm and the individuals involved. Thirdly, management often gained important experience from conversations with counterparts at the Users' Groups organised by most turnkey suppliers.

On the basis of discussions with both management and operators in firms using $\mathrm{CAD}$, it is possible to simulate a series of learning curves, as is done in Figure 1 below. Insofar as operators are concerned, learning occurs in a series of steps. At around three months, or earlier, most operators are up to the level of productivity of manual systems. There is then a short period of retrenchment while the operator assimilates the newlylearnt basic operating skills which are threreafter continually improved via the assistance of menus, until around six months. Then the operator begins to take advantage of the sub-designs stored in the CAD system and makes more effective use of analytical programs. Most users reported that by the end of the first year, most operators were about as efficient with the system as they could ever get-further benefits depended upon the back-up provided by systems 
organisation. There was, however, some difference in the views of users about whether the period of individual retrenchment was associated with a flattening of the curve or a temporary decline in productivity-since we encountered sufficient of these latter views we believe that a temporary fall-off in productivity is a common experience.

One of the functions of management is to iron-out these periods of individual retrenchment and thereby to increase the general productivity of the system by moving the industrial operators to a more desirable learning curve. This can be done by providing special assistance to operators experiencing difficulties, but it also sometimes appears to involve the slowing down of particular rapid-learners who, by pulling ahead of their colleagues, have the effect of imbalancing the system. But managment also has a variety of other functions (described above) involving the eastablishment of procedures which affect the learning curve of particular operators.

\section{figure 1}

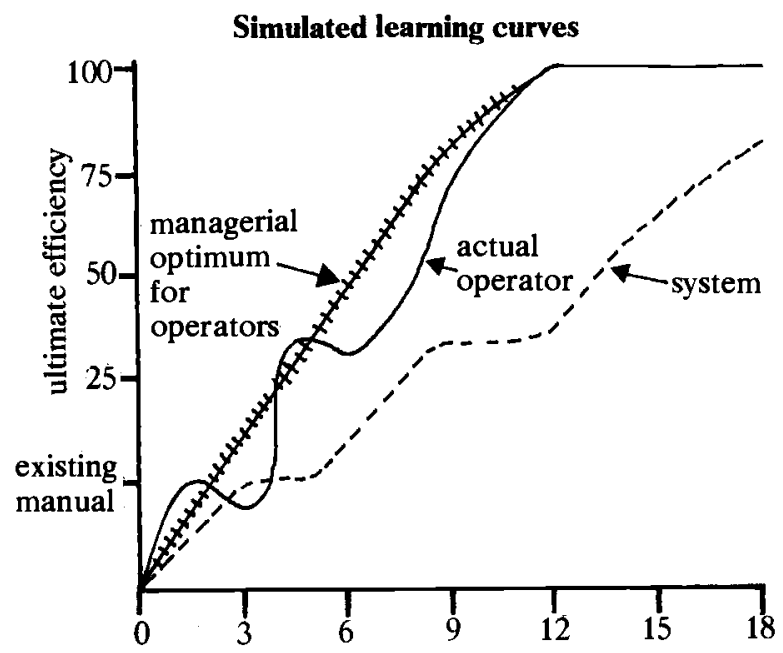

But ultimately, as we have repeatedly pointed out, the productivity of the CAD system depends upon organisational changes in the system, including complementary adjustments in the other spheres of the firm, that is information control and production/ distribution. Without these, the full benefits of the CAD system cannot be realised. The time span within which management is able to comprehend the changes which are necessary, and then to implement them, is generally, but not always, longer than those involved in the individual learning curve. However there are, as with the operator learning curve, periods of flatness in the growth of system productivity.

\section{Conclusions}

On the basis of a detailed empirical investigation in the US and Europe it is clear that the use of CAD technology is essential in many sectors if firms are to compete in world markets. Since many of the benefits offered by CAD technology (reduced lead time, better quality products and reduced costs) are also to be obtained via the introduction of microelectronics in other sectors (eg machine tools and garments-see Jacobsson's and Hoffman and Rush's contributions), we believe that this represents a common pattern.

At first glance, as our more detailed discussion of the skill implications suggests, developing countries have few problems in mastering the use of the new technology. If anything at the level of operation (rather than back-up) microelectronics related innovations are easier to use than the craft-based systems which they replace. If this is so, it suggests that the major concern for developing countries over the coming decade lies in maintaining access to developed country markets in the context of growing levels of structural unemployment throughout the globe.

But on deeper consideration it is evident that whilst the absolute skill barrier to the use of CAD (and other microelectronics technologies) is slight, a close 'handholding' relationship between users and suppliers and between different users is absolutely essential for the efficient use of the technology. Consequently because of the established presence of CAD suppliers and systems in developed countries, it is likely that at least in the foreseeable future the technology will spread less rapidly to developing countries than to developed ones. It comes as no surprise, therefore, to learn that of the CAD systems surveyed in the wider study only 32 out of over 6,000 systems have gone to developing countries. And of these 32 most went to either TNC subsidiaries in the petroleum industry or to governments aiming to map their countryside (with USAID technical assistance) to assist in counter-insurgency programmes.

Therefore to the extent that $\mathrm{CAD}$ is representative of the use of microelectronics in industrial products and processes, we can anticipate that the diffusion of microelectronics will be associated with a reduction in developing country comparative advantage. This will not be a result of any absolute skill barriers to utilisation, but rather as a consequence of the close organic link required between suppliers and users, and between different users of radically new technologies. The origins of these technologies in developed countries make it likely that the new technologies will develop and diffuse more rapidly in these same economies.

\section{References}

Kaplinsky, R., 1982, The Impact of Electronics on the Inter national Division of Labour-the illustrative case of computer aided design, Francis Pinter, London 